\title{
An assessment of the use of patient reported outcome measurements (PROMs) in cancers of the pelvic abdominal cavity: identifying oncologic benefit and an evidence-practice gap in routine clinical practice
}

Miss Charlotte L. Moss ${ }^{*}$ (D) Ajay Aggarwal2,3, Asad Qureshi², Benjamin Taylor², Teresa Guerrero-Urbano² and Mieke Van Hemelrijck'

\begin{abstract}
Background: Patient reported outcome measurements (PROMs) are emerging as an important component of patient management in the cancer setting, providing broad perspectives on patients' quality of life and experience. The use of PROMs is, however, generally limited to the context of randomised control trials, as healthcare services are challenged to sustain high quality of care whilst facing increasing demand and financial shortfalls. We performed a systematic review of the literature to identify any oncological benefit of using PROMs and investigate the wider impact on patient experience, in cancers of the pelvic abdominal cavity specifically.

Methods: A systematic review of the literature was conducted using MEDLINE (Pubmed) and Ovid Gateway (Embase and Ovid) until April 2020. Studies investigating the oncological outcomes of PROMs were deemed suitable for inclusion.

Results: A total of 21 studies were included from 2167 screened articles. Various domains of quality of life (QoL) were identified as potential prognosticators for oncologic outcomes in cancers of the pelvic abdominal cavity, independent of other clinicopathological features of disease: 3 studies identified global QoL as a prognostic factor, 6 studies identified physical and role functioning, and 2 studies highlighted fatigue. In addition to improved outcomes, a number of included studies also reported that the use of PROMs enhanced both patient-clinician communication and patient satisfaction with care in the clinical setting.
\end{abstract}

Conclusions: This review highlights the necessity of routine collection of PROMs within the pelvic abdominal cancer setting to improve patient quality of life and outcomes.

Keywords: Patient reported outcome measurements, Health related quality of life, Prognostic factors, Overall survival, Pelvic abdominal cancers

\footnotetext{
*Correspondence: charlotte.moss@kcl.ac.uk

${ }^{1}$ King's College London, School of Cancer and Pharmaceutical Sciences,

Translational Oncology and Urology Research (TOUR), Guy's Hospital, 3rd

Floor Bermondsey Wing, Great Maze Pond, London SE1 9RT, UK

Full list of author information is available at the end of the article
}

\section{Introduction}

The incidence of cancers of the pelvic abdominal cavity (broadly urological, gynaecological, colorectal, gastric, hepatic and pancreatic tumour types) is increasing as population life-expectancy increases [1]. As of 2018, permits use, sharing, adaptation, distribution and reproduction in any medium or format, as long as you give appropriate credit to the original author(s) and the source, provide a link to the Creative Commons licence, and indicate if changes were made. The images or other third party material in this article are included in the article's Creative Commons licence, unless indicated otherwise in a credit line to the material. If material is not included in the article's Creative Commons licence and your intended use is not permitted by statutory regulation or exceeds the permitted use, you will need to obtain permission directly from the copyright holder. To view a copy of this licence, visit http://creativecommons.org/licenses/by/4.0/. The Creative Commons Public Domain Dedication waiver (http://creativeco mmons.org/publicdomain/zero/1.0/) applies to the data made available in this article, unless otherwise stated in a credit line to the data. 
prostate and bowel were two of the most commonly diagnosed cancers worldwide and, with treatments emerging and evolving, survival rates for the majority of tumour types continue to increase [2]. Such increasing survival rates place huge importance on ensuring adequate levels of quality of life for patients, as life-extending cancer treatment regimens may result in increased symptom burden and decreased physical and emotional functioning.

Patient reported outcome measures (PROMs) are emerging as an important component for patient management in the cancer setting. PROMs are standardised and validated self-complete instruments which broadly provide patient perspective on domains relating to quality of life, symptom management, patient functioning and patient satisfaction with care or perceptions of care $[3,4]$. Empirical evidence supports the use of PROMs in the clinical setting to identify patient concerns, enhance patient-clinician communication and improve patient satisfaction with care in the clinical setting $[5,6]$. The widespread use of PROMs routinely is, however, limited, with the majority of use occurring within randomised control trials (RCTs) where PROMs are used to monitor health status and quality of life before, during and after experimental treatments. Additionally, PROMs are used in this setting to assess whether the survival benefits of a specific treatment may outweigh any potential side effects or for choosing between treatment options which offer similar survival benefit [7-9].

The use of PROMs in routine clinical practice is limited as healthcare services are challenged to sustain high care quality, whilst also facing increased demand and financial shortfalls [10]. Moreover, there exists a lack of established standard on what PROMs should be utilised in which setting and how benefit should be measured [11]. Indeed, despite the well-known benefits of PROMs in terms of quality of life, less is understood about the potential oncological benefits of utilising PROMs routinely in the clinical setting. Emerging evidence suggests a potential role for PROMs as independent prognostic tools which, when used alongside clinicopathological information, may provide clinicians with a more valid and comprehensive understanding of patient disease [12,13]. A deeper understanding of this potentially prognostic function is imperative in order to develop a rationale for the widespread implementation of routine collection of PROMs within the clinical setting.

We therefore sought to systematically review the literature to determine current understanding of the potential prognostic role of PROMs, with reference to tumours of the pelvic-abdominal cavity specifically. Studies were critically appraised to identify any measurable oncologic benefit and are described using a narrative presentation.

\section{Methods}

\section{Search strategy and inclusion criteria}

The research question, search strategy, and inclusion and exclusion criteria were developed prior to commencement of literature searching in April 2020. Relevant studies were identified by conducting searches of Medline (Pubmed) and Ovid Gateway (Embase and Ovid) using the listed search terms from inception until April 2020. A comprehensive set of search terms was compiled and is included as a supplement (Additional file 1: Appendix A). After searching, the list of returned articles was further filtered to include only articles published in the English language and studies referring to humans alone. Reference lists of included articles were also checked for additional relevant literature.

The full inclusion and exclusion criteria are presented in Table 1. The following inclusion criteria was utilised: a randomised control trial, an observational study or an original article, written in the English language, and investigating the oncological outcomes of PROMs in patients with urological, gynaecological, colorectal, pancreatic, gastric or hepatic tumour types. Commentaries, author's replies, reviews, supplements, editorials and systematic reviews were excluded. Studies that included patients with cancers other than pelvic abdominal tumours were included on the condition that the relevant pelvic abdominal cancer data could be isolated.

All duplicates were removed, and articles were reviewed by title, abstract and full text by the first author (CM). A second author (MVH) subsequently reproduced the results of the search strategy before independently undertaking screening of all articles included for full text review. In case of disagreement, a third independent reviewer (TGU) was consulted to confirm the final list of included studies. Management of the screening process occurred using Microsoft Excel.

\section{Quality assessment}

Initially, the quality of each study was assessed by $\mathrm{CM}$ using quality assessment tools developed by the Joanna Briggs Institute (JBI) (http://joannabriggs.org/research/ critical-appraisal-tools.html). The JBI have developed various tools for assessing the quality of quantitative studies that are appropriate for use in systematic reviews to appraise questions of aetiology and risk. The purpose of such appraisals is to broadly assess the methodological quality of a study and to determine the extent to which each study addresses the possibility of bias in its design, conduct and analysis. Owing to the varying design of the included studies, JBI critical appraisal checklists for cohort studies, randomised control trials and case series were utilised. The appraisals are included separately as Additional file 1: Appendix B1, B2 and B3. Following 
Table 1 Inclusion and exclusion criteria for screening

\begin{tabular}{lc}
\hline Inclusion criteria & Exclusion criteria \\
\hline Peer reviewed paper & Non full text articles \\
Published at any time before April 2020 & Systematic Reviews \\
& \\
Quantitative analyses & Studies in which data pertaining to any of \\
Includes participants: & the included tumour types could not be \\
Patients diagnosed with: & isolated \\
Any urological cancer & \\
Any gynaecological cancer & \\
Any colorectal cancer & \\
Any gastric cancer & \\
Any hepatic cancer & \\
Any pancreatic cancer & \\
Disease stage: any & \\
Treatment regimen: any & \\
Demographic: any & \\
Quantitative studies & \\
Design: & \\
Randomised control trial & Prospective cohort \\
Non-randomised control trial & \\
Cross sectional & \\
Variables examined: & \\
Prognostic potential of PROMs & \\
Specific QoL instruments with prognostic potential & \\
\hline
\end{tabular}

critical appraisal by CM, a second author (MVH) independently assessed the quality of each included study using the JBI critical appraisal tools. Each of the studies were subsequently discussed to identify any differences in opinion with consultation from a third author (TGU).

\section{Results}

\section{Evidence synthesis}

As detailed in the PRISMA flow diagram (Fig. 1), the search strategy identified 2191 articles. Following the removal of 24 duplicates, and using the inclusion criteria outlined above, 2167 articles were screened by title. A further 228 records subsequently underwent abstract review before 43 were assessed based on the full text. Overall, 21 articles were deemed suitable for inclusion. Full details of the included studies are presented in Table 2.

Of the 21 included studies, 7 were randomised control trials and 14 were observational in design. The articles were published between 1997 and 2018 and included sample sizes ranging from 47 patients to 2603. Seven of the studies were conducted on patients with pancreatic cancer; 6 on patients with a diagnosis of colorectal cancer; 5 on prostate cancer patients; 4 on urological cancers (including bladder and renal cancers); 3 on gynaecological cancers and 2 on gastric cancer patients. Although the studies were conducted worldwide, a large proportion
$(10 / 21)$ were published in the United States. The treatment setting of each included study also differed; 5 of the studies included patients undergoing chemotherapy regimens, 3 were conducted in the surgical setting, one study included survivors only and two studies included patients receiving targeted therapy or hormonal therapy/ radiotherapy.

\section{Data presentation}

Due to a lack of study homogeneity relating specifically to the patient reported outcome measurements utilised, quantitative synthesis was not viable and hence results are presented in a narrative style.

\section{Randomised control trials}

Of the seven RCTs included [14-20], two were interventions implemented in pancreatic cancer populations [15, $16]$, two were undertaken in a colorectal cancer setting $[14,17]$, one in bladder cancer [19], one in gastric cancer [18] and one in prostate cancer [20]. Two studies were based on the same RCT (Clinical Outcomes Surgical Therapy trial NCCTG 93-46-53), but investigated the prognostic significance of measuring baseline patient reported outcomes (PROs) in slightly different capacities [14, 17]. These two studies utilised results from a surgical RCT where the intervention compared open versus laparoscopic techniques in terms of post-operative 


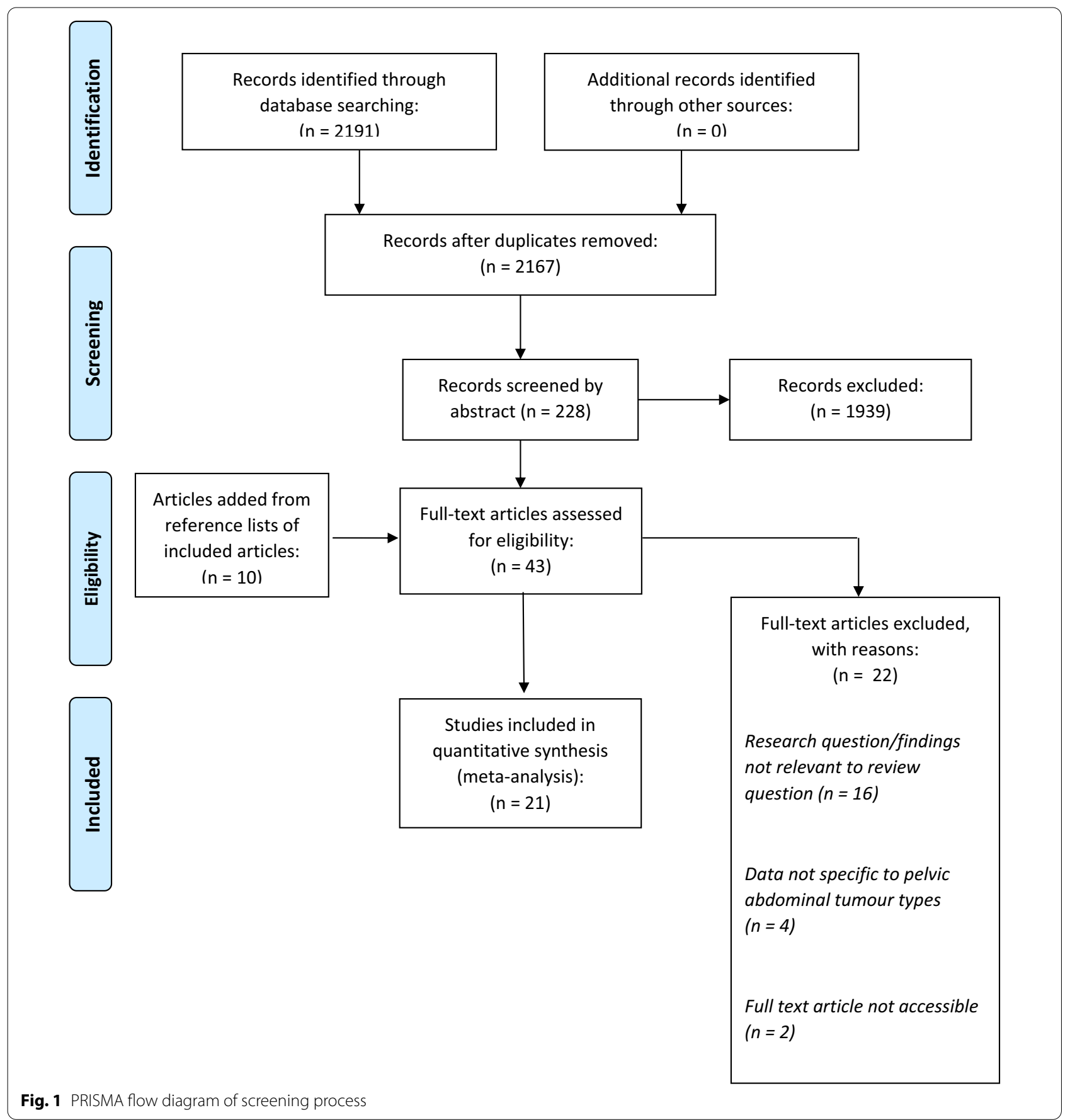

complications and patient outcomes. Both studies used the Symptom Distress Scale and QOL Index recorded preoperatively to demonstrate the significant prognostic impact of such quality of life (QoL) measurements on the overall survival (OS) of colorectal cancer patients, and to demonstrate that these measures are more sensitive than clinician reported outcomes (CROs) in predicting mortality. Of note, longer term combined analysis of patients in both arms of the intervention identified lower patient baseline outlook as associated with decreased overall survival.

Four RCTs were secondary analyses of chemotherapy interventions whereby pancreatic, bladder and gastric cancer patients were randomised to receive varying regimens of cytotoxic therapy [15, 16, 18, 19]. Noteworthy observations from these studies included the prognostic 


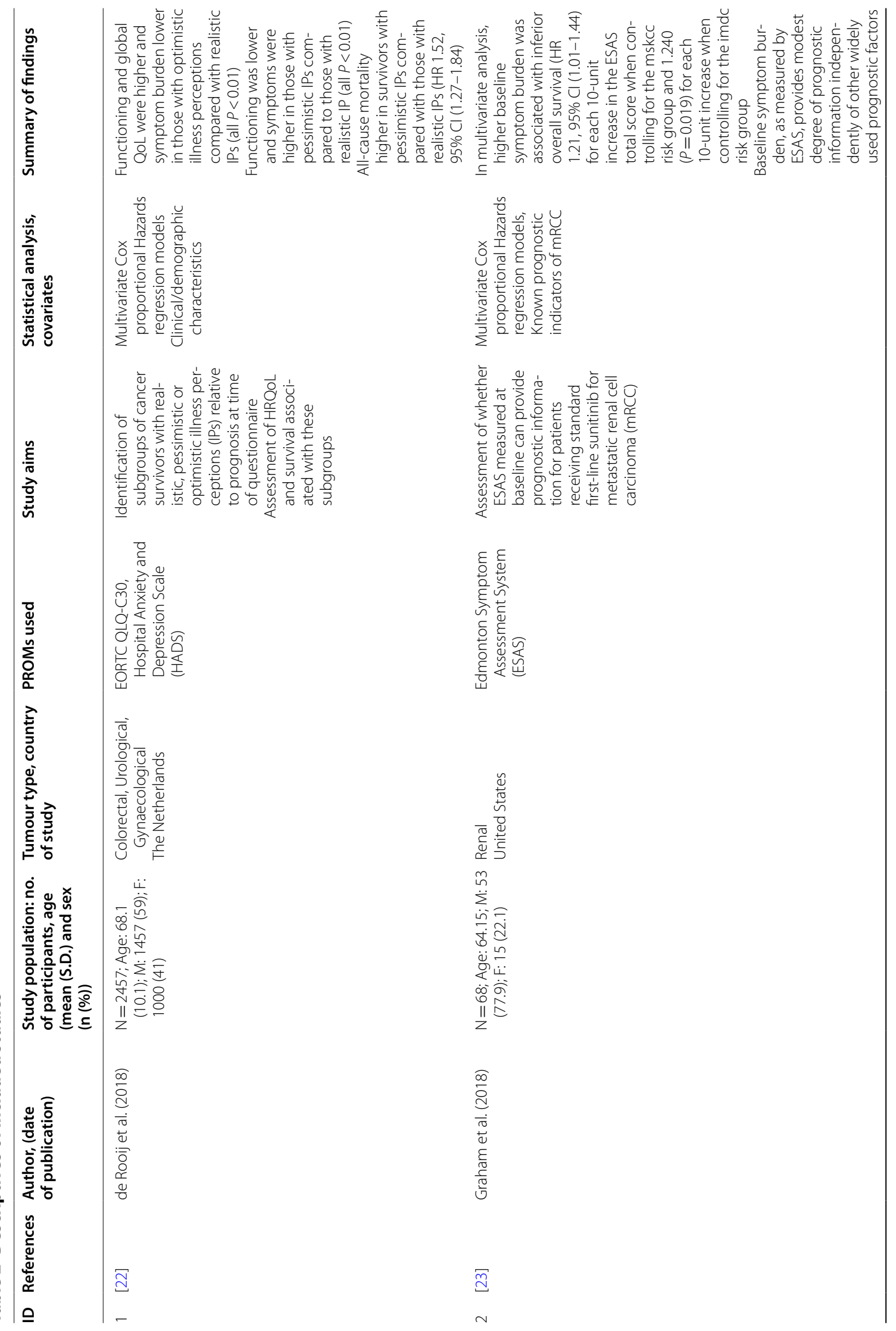




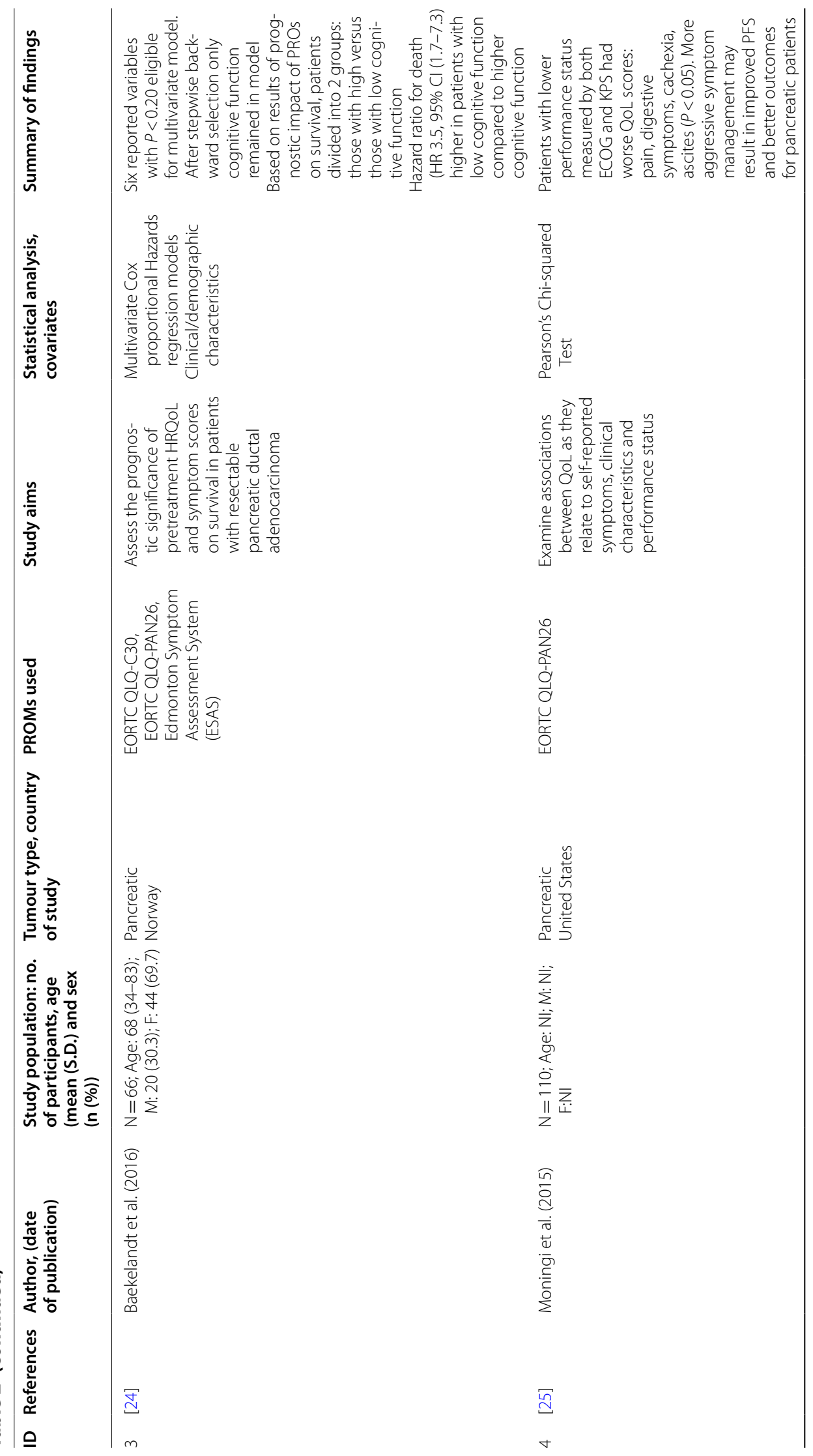




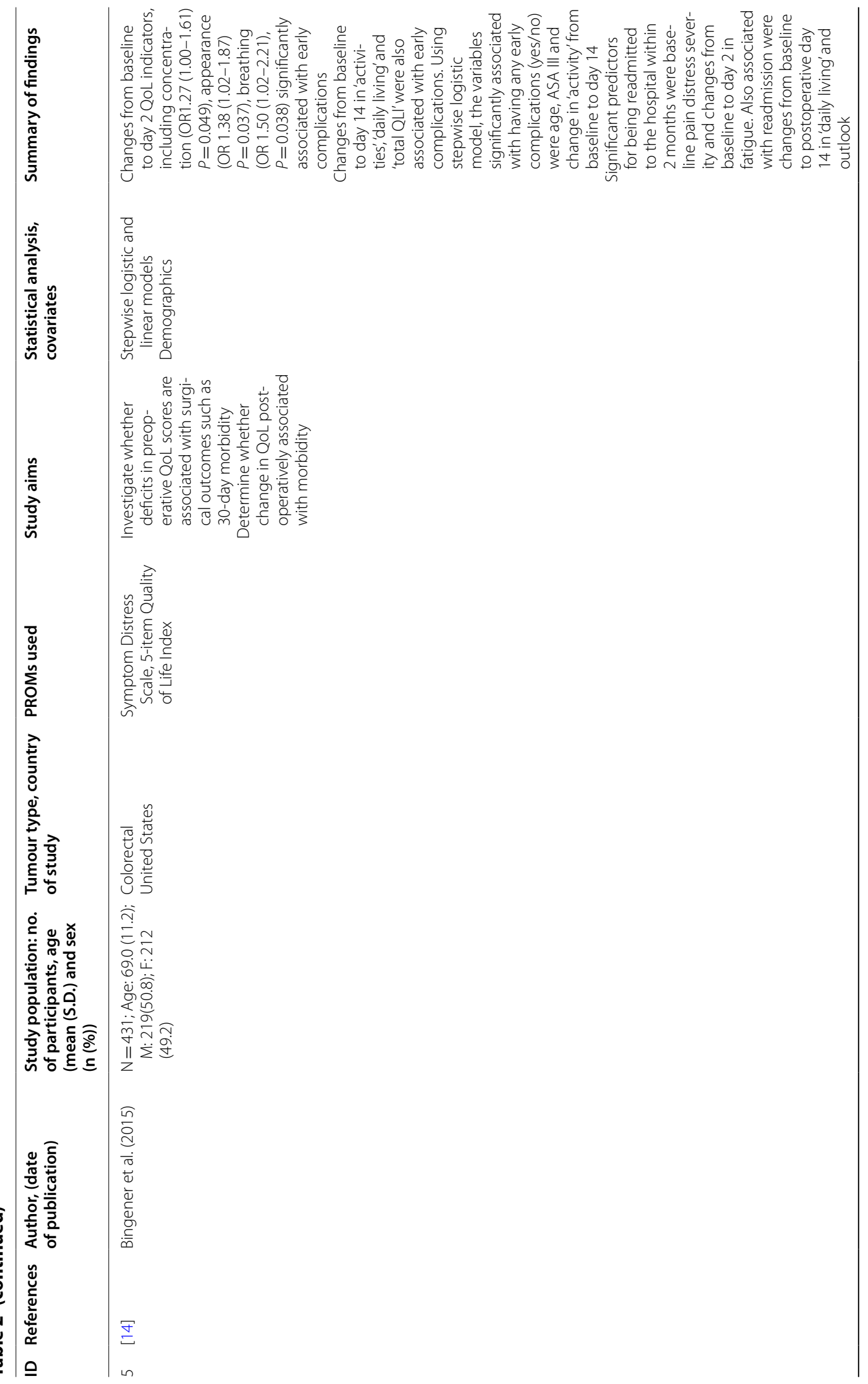




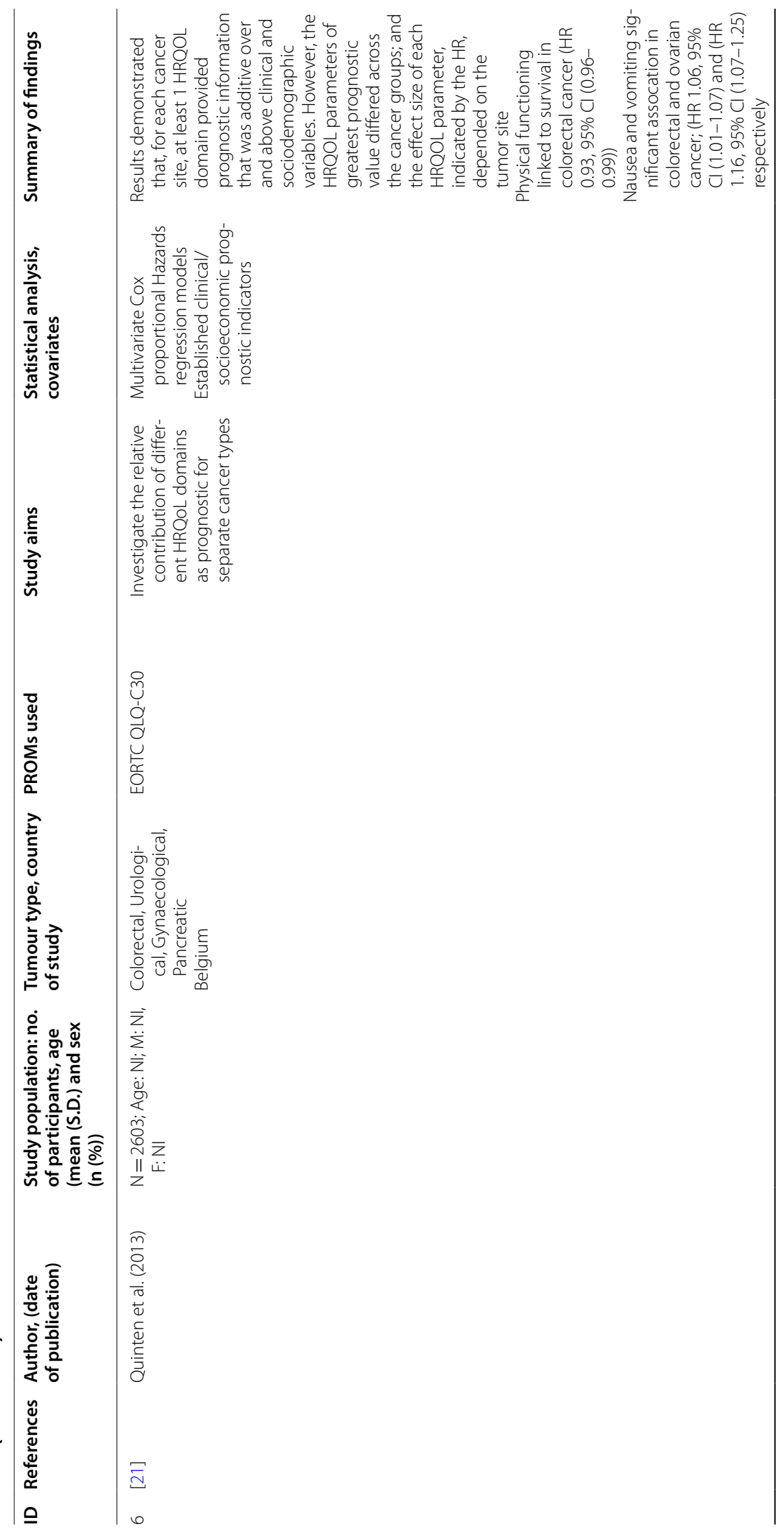




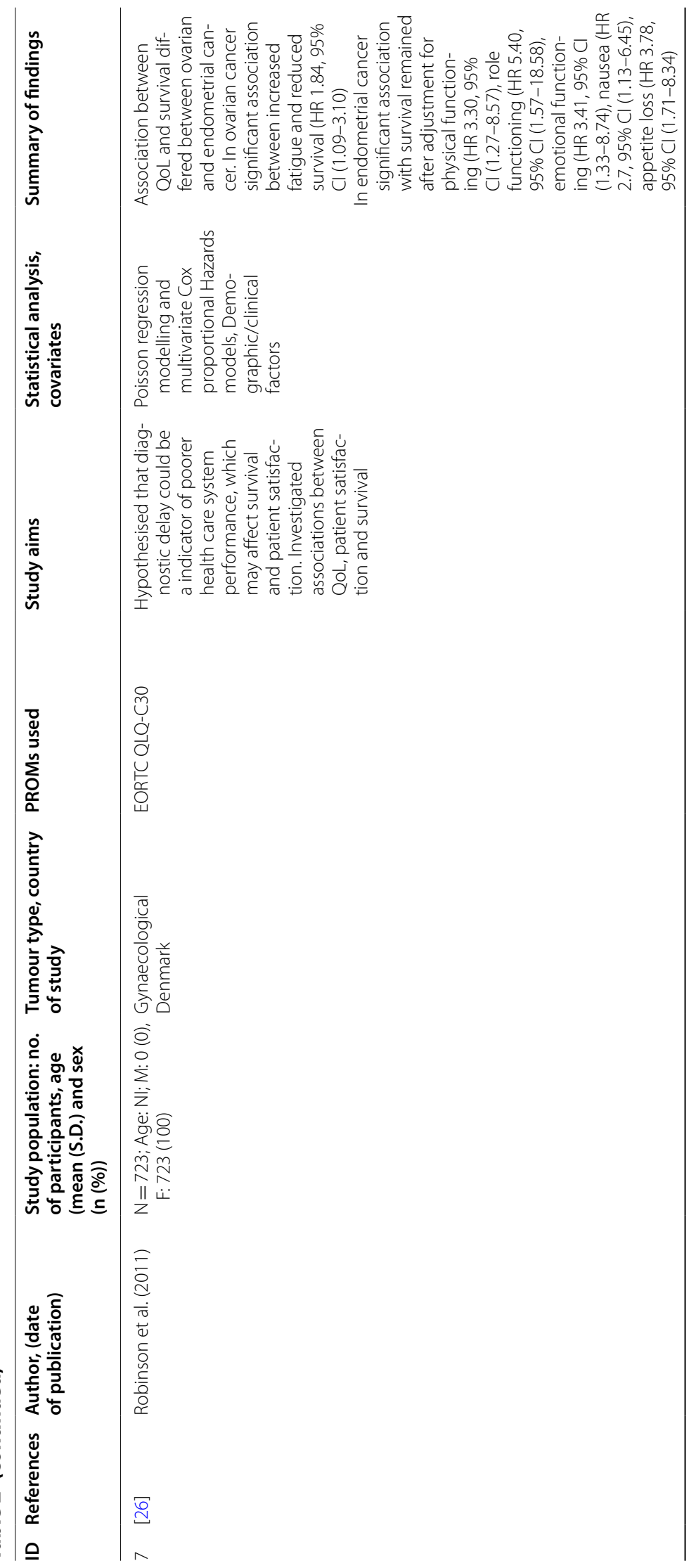




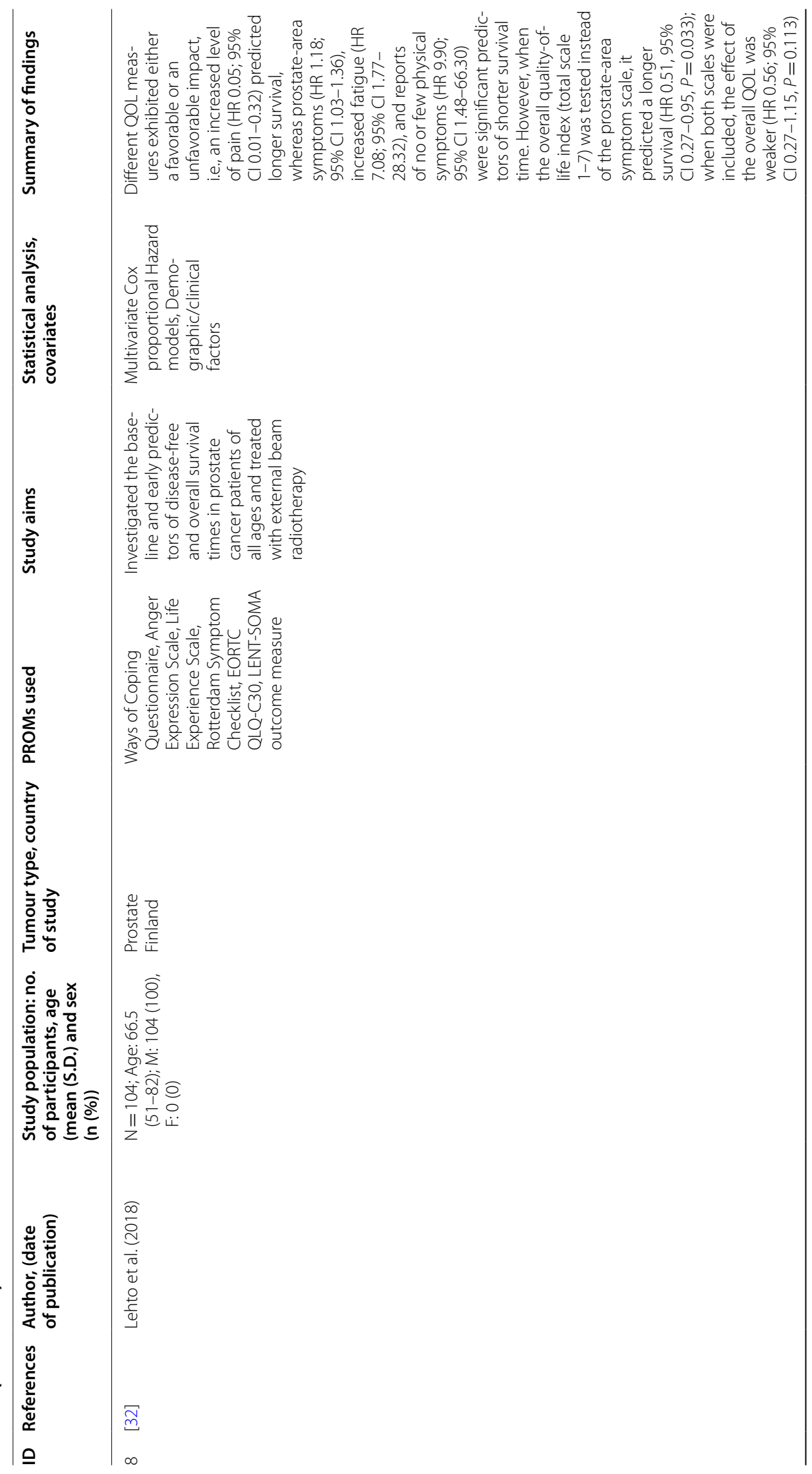




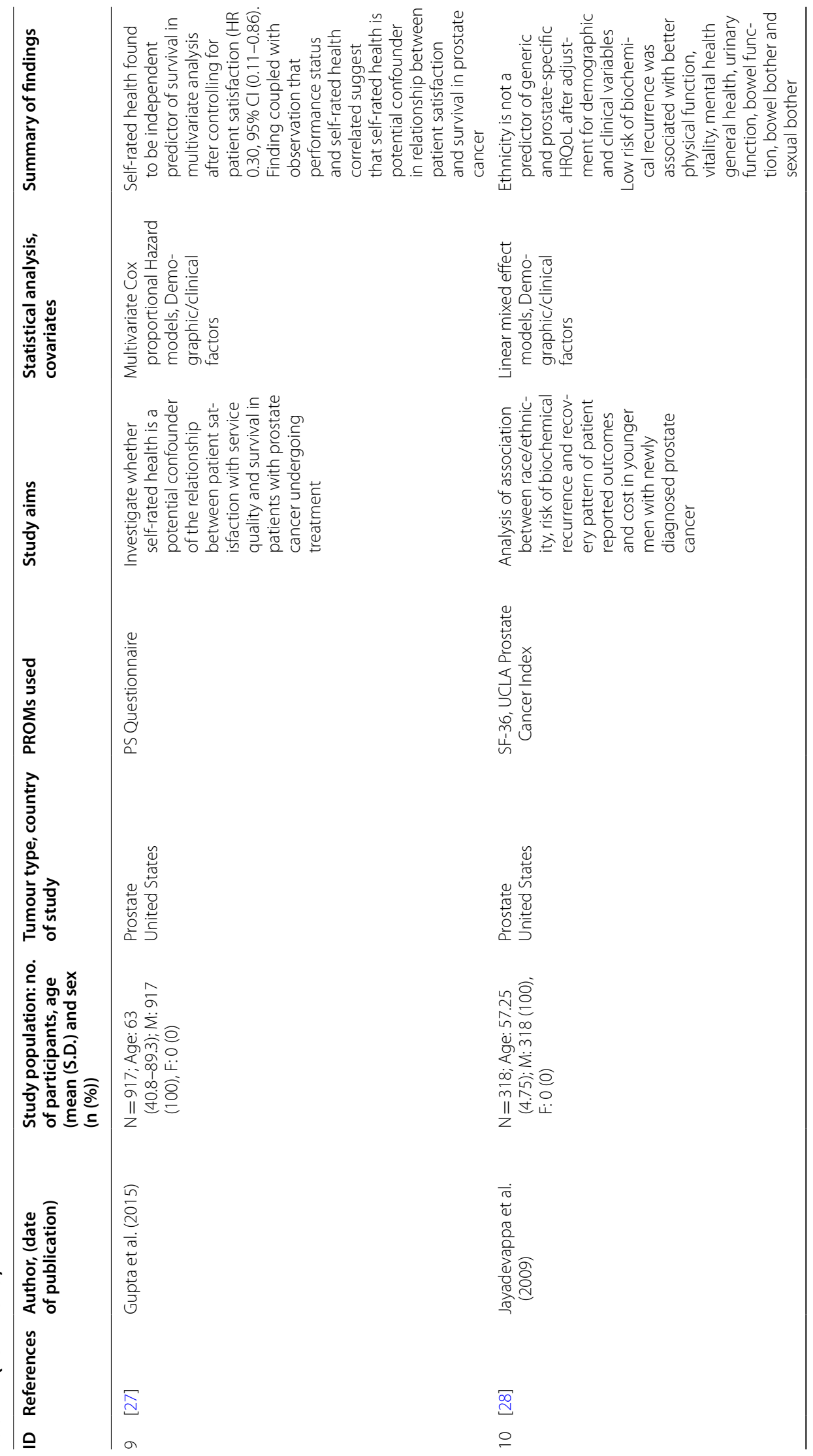




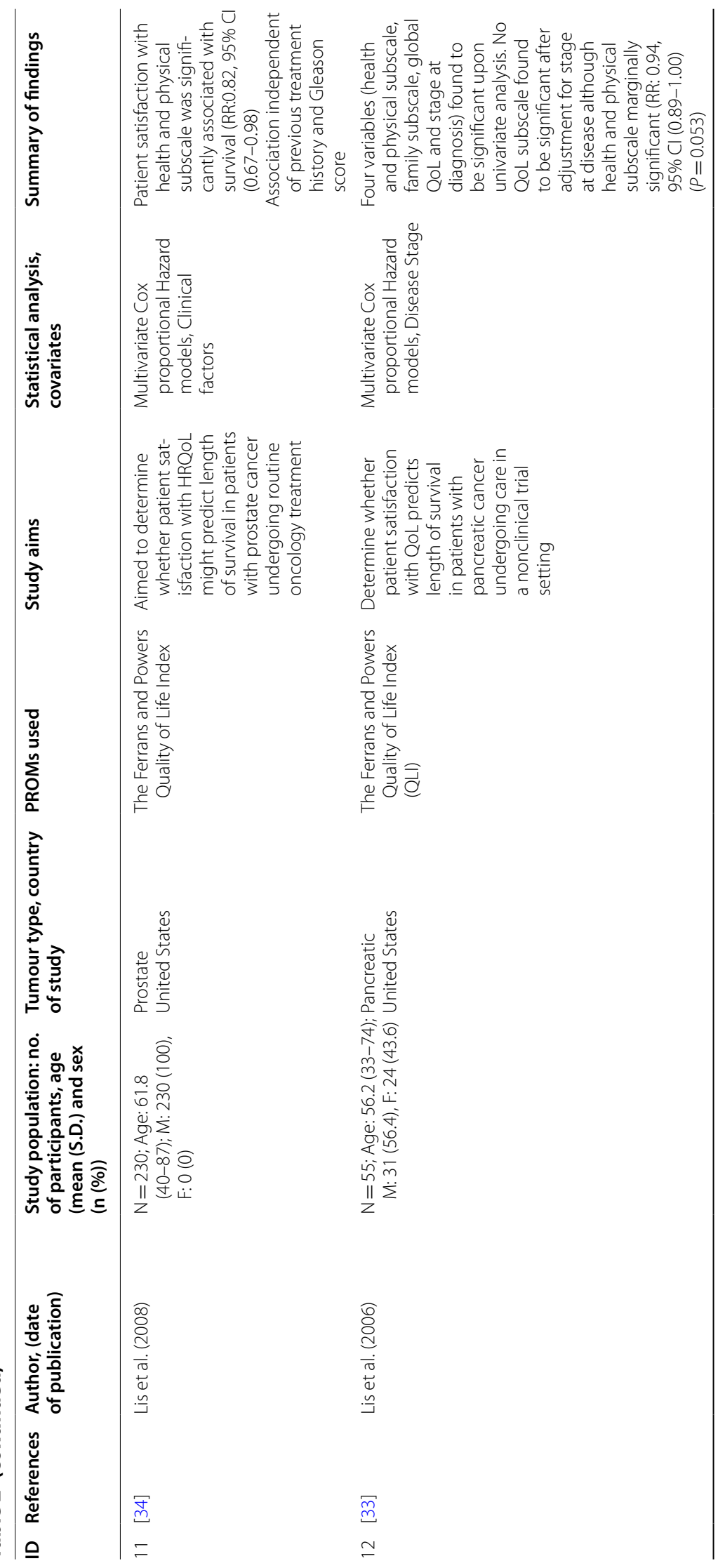




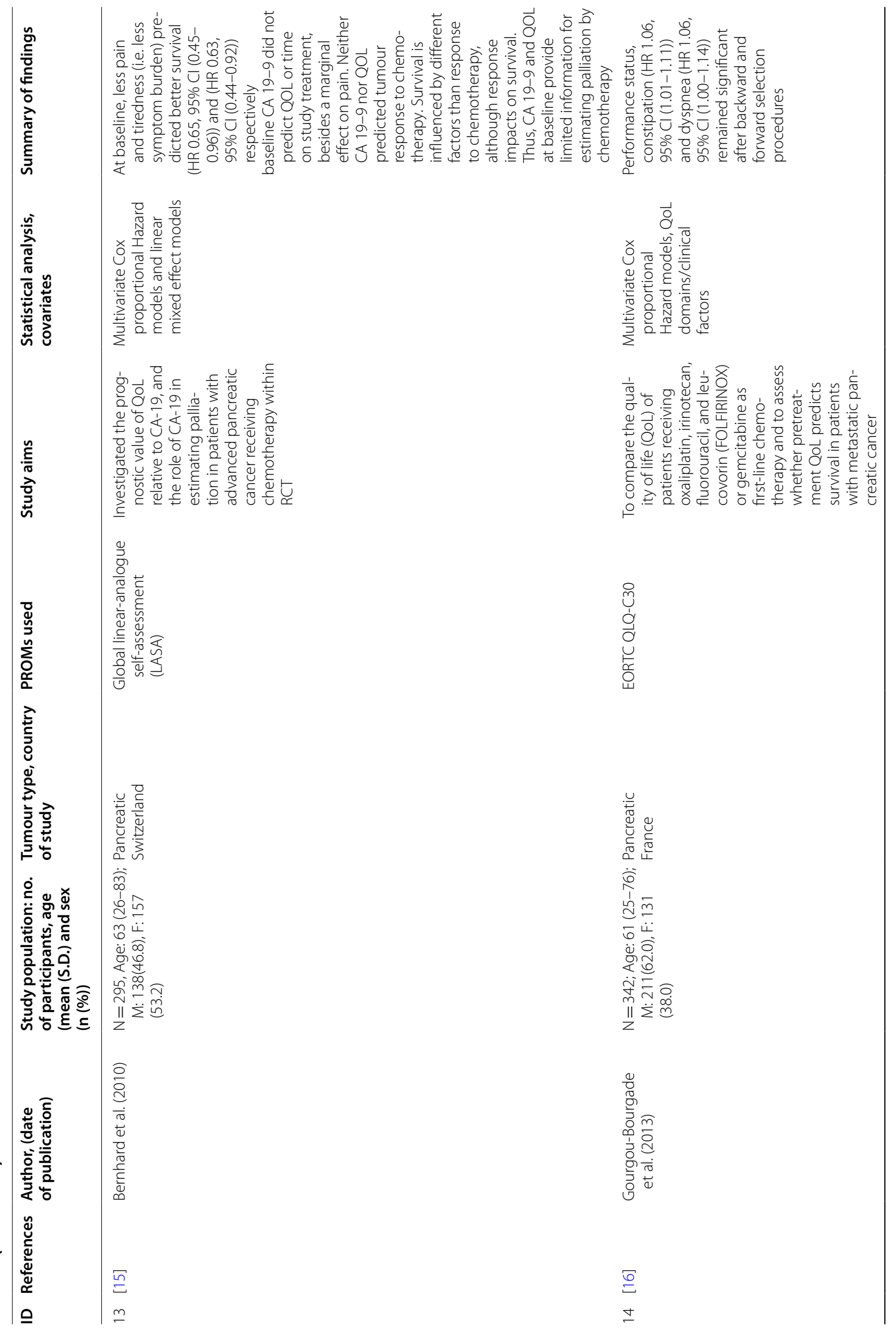




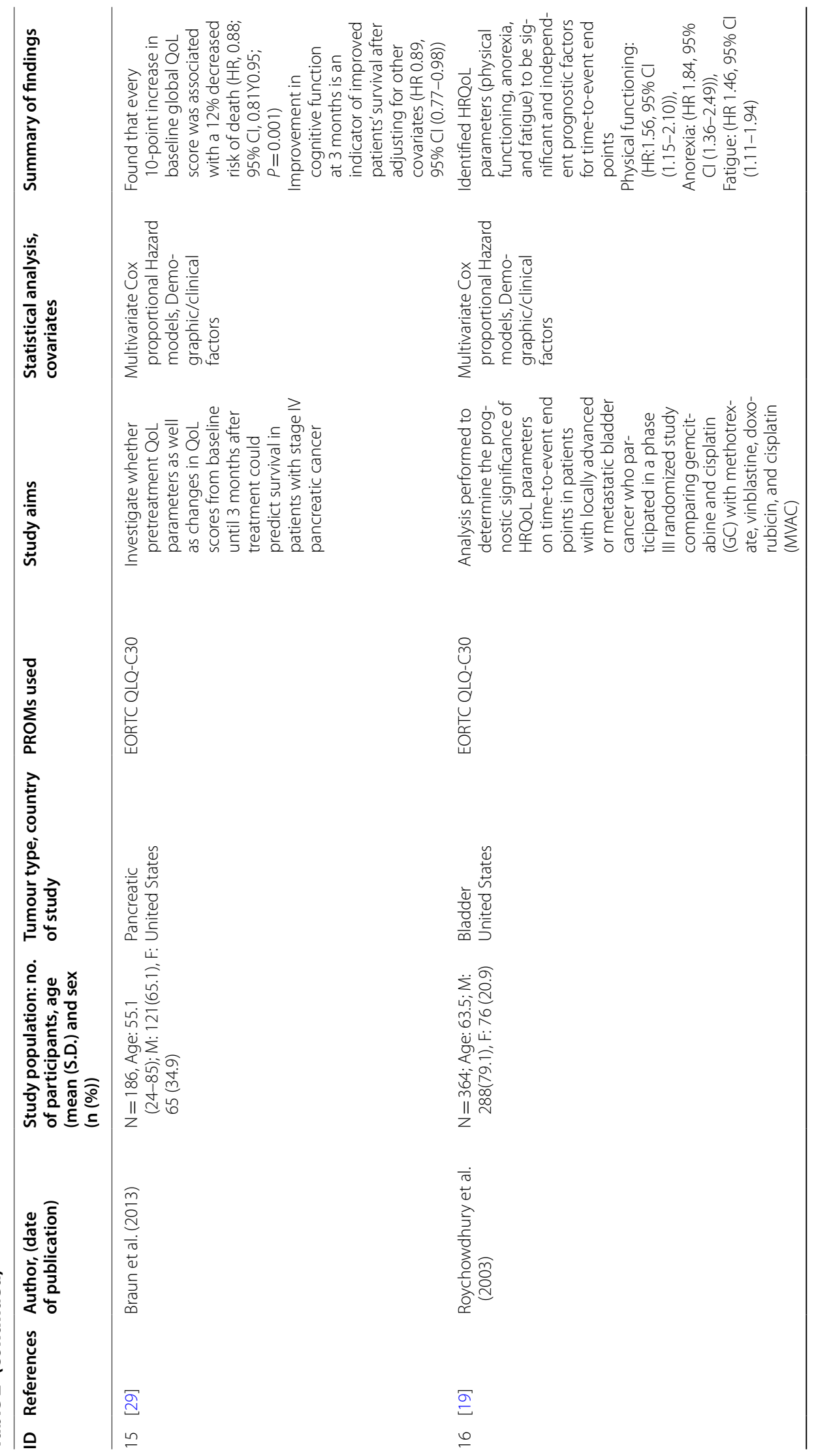




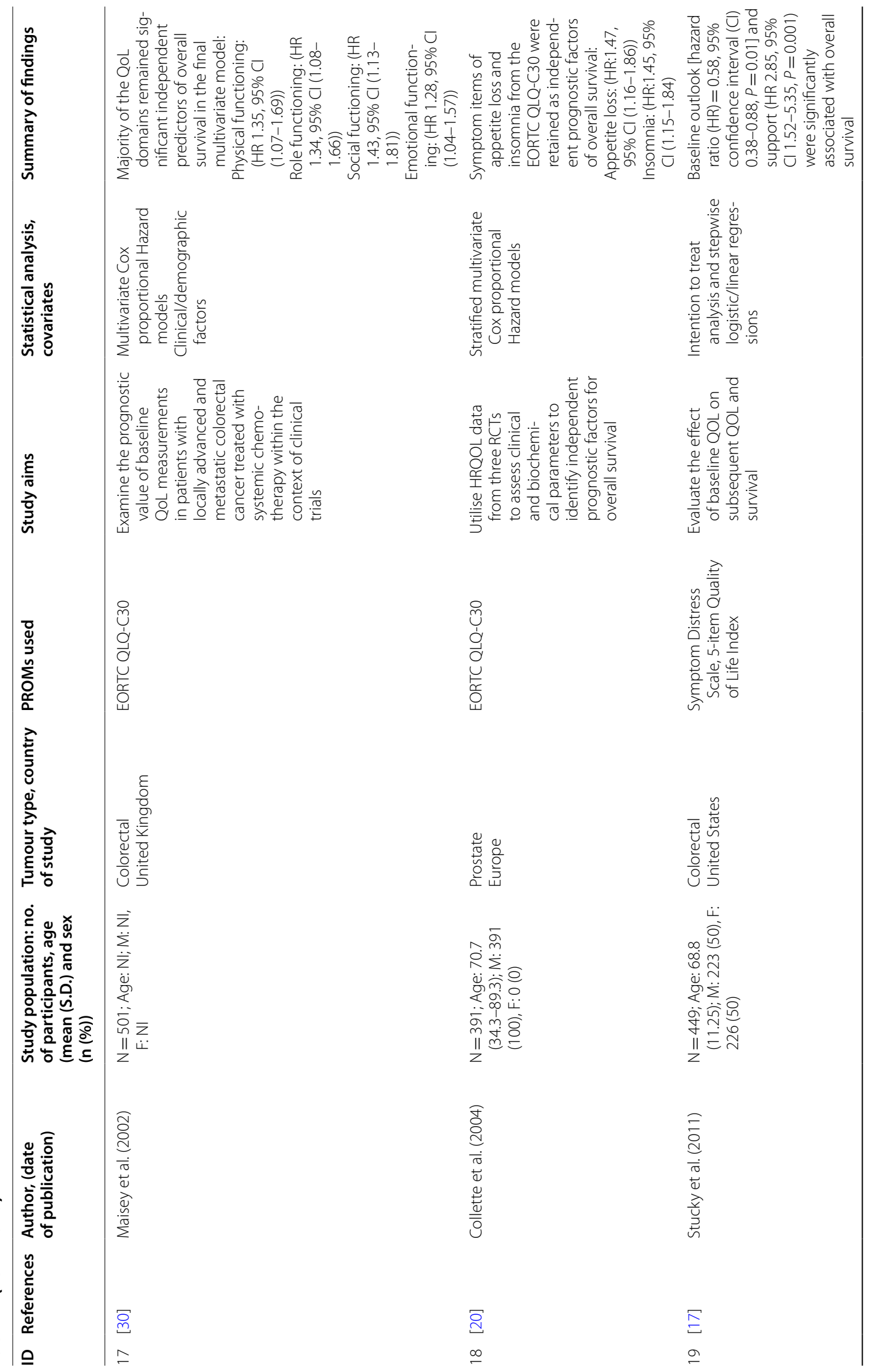




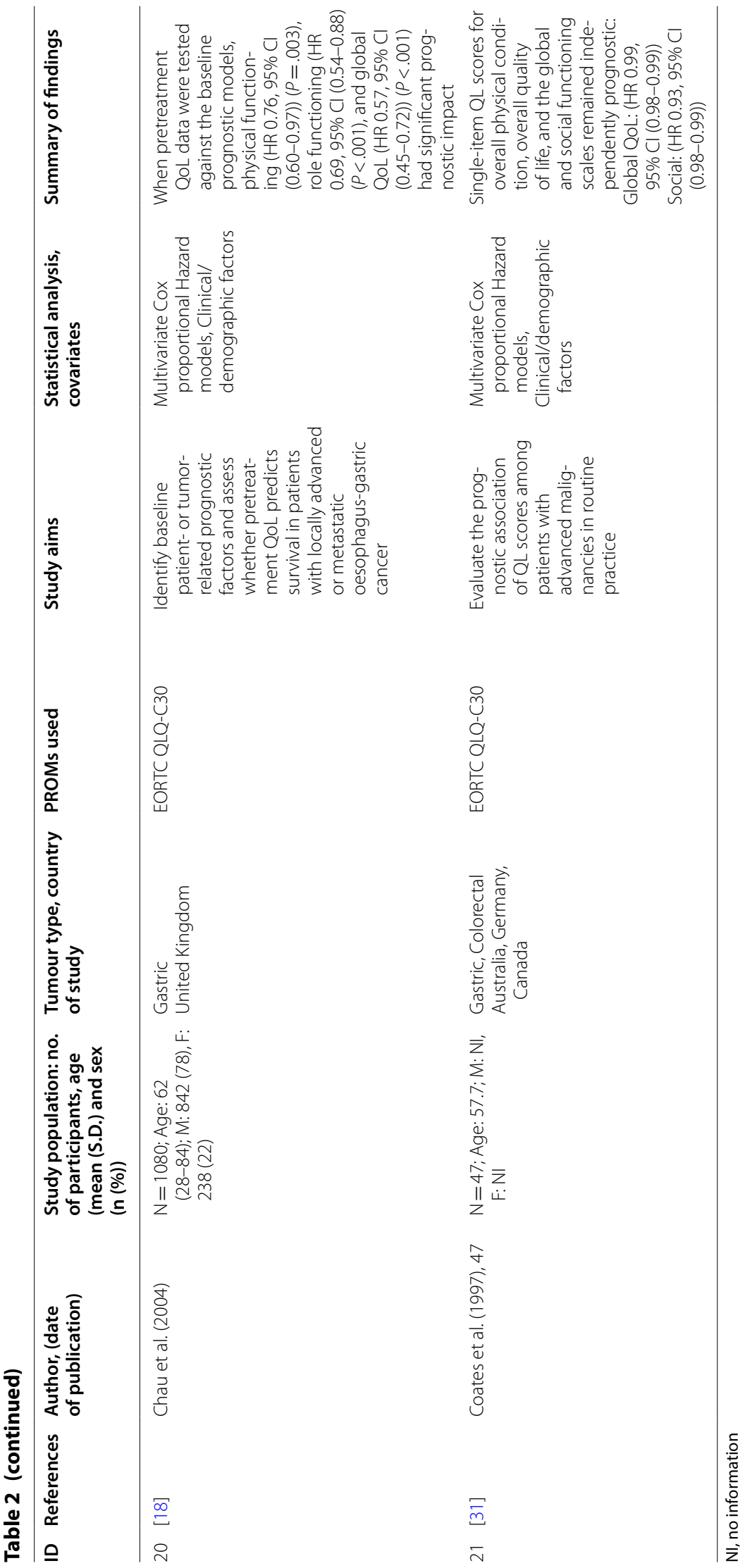


significance of pain and fatigue as independent indicators for survival in pancreatic cancer, although these measures were found to be less prognostic than the carbohydrate antigen 19-9 (CA-19) [15]. In addition, this study surmised that QoL did not predict tumour response to chemotherapy.

A second RCT for pancreatic cancer patients utilised the EORTC QLQ-C30 questionnaire to identify no significant difference in QoL in treatment arms over time [16]. Subsequent multivariate analysis identified physical functioning, constipation and dyspnoea as significant prognostic factors in this patient cohort, with severely impaired physical functioning imparting the strongest negative effect on overall survival [16]. In the context of the bladder cancer RCT, Roychowdhury et al. also utilised the EORTC QLQ-C30 questionnaire to demonstrate physical functioning as a significant and independent prognosticator for time to event endpoints [19]. This RCT also identified a potential prognostic role for fatigue and anorexia in both treatment arms. Interestingly, in univariate analysis, higher role functioning was identified as a positive prognostic factor but, paradoxically, in the multivariate model longer overall survival was associated with lower role functioning.

In the setting of gastric cancer, three RCTs assessing fluorouracil-based combination chemotherapy were combined to investigate whether pretreatment QoL predicts survival in patients with locally advanced or metastatic disease [18]. In this study, and similarly to the other RCTs, better physical and role functioning predicted increased survival. Data was collated using the EORTC QLQ-C30 instrument and suggested the role of global QoL score as a strong prognostic factor.

In contrast to the other RCTs, a European hormonal therapy/radiotherapy intervention in prostate cancer identified that HRQoL factors, as measured by the EORTC QLQ-C30 instrument, did not accurately predict overall survival once clinical and biochemical factors were accounted for [20]. Despite baseline global health status being associated with overall survival in other tumour types, this relationship was not demonstrated in this study.

\section{Cohort studies}

Full details of the 11 included cohort studies are contained in Table 2. One was in the context of aggregated RCT data [21] and 10 were original cohorts [22-31]. The tumour breakdown of these patient cohorts were as follows: five analyses included urological cancer patients [21-23, 27, 28], four colorectal [21, 22, 30, 31], three gynaecological $[21,22,26]$, three pancreatic $[24,25,29]$ and one gastric cancer cohort [31].
An analysis by Jayadevappa et al. of 318 younger prostate cancer patients identified that low risk biochemical recurrence is mostly indicative of better generic and prostate specific HRQoL [28]. Similarly, an American analysis of 917 prostate cancer patients demonstrated that patient self-rated health is a potential confounder in the relationship between patient satisfaction and survival; thus suggesting that future studies investigating patient satisfaction should include collection of selfrated health modules [27]. In renal cancer, a study by Graham et al. observed that baseline use of the Edmonton Symptom Assessment System provides a modest degree of prognostic information about survival, independently of other widely used prognostic models [23]. These results were consistent with previously reported data examining the prognostic function of the FACTKSI instrument.

In pancreatic cancer patient cohorts, analyses further suggested a role for the EORTC QLQ-C30 instrument to provide prognostic information for survival [29]. As reported above, baseline global health was an independent prognosticator and, interestingly, the study found that the probability of survival increased significantly if cognitive function improved within three months of treatment [29]. Of note, an analysis of 66 Norwegian pancreatic cancer patients also demonstrated that cognitive function, as measured by the Edmonton Symptom Scale, was an independent prognostic factor [24].

In the context of colorectal cancer, a large UK study of 501 patients identified that patients with high baseline global QoL have a 1-year survival that is almost double that of patients with a score below median value [30]. Multivariate analysis demonstrated that symptom and functioning measures, as recorded using the EORTC QLQ-C30, appeared to be a stronger predictor of overall survival compared to clinician measured performance status. A smaller analysis of 47 patients with advanced gastric or colorectal cancers identified that overall physical condition and global QoL was an independent prognosticator of overall survival [31]. Indeed, further preliminary analyses demonstrated an association between psychological response to cancer and survival.

A Danish analysis of a gynaecological patient cohort investigated patient quality of life and satisfaction as an alternate avenue for exploring the consequences of diagnostic delay [26]. This study identified that, in ovarian cancer patients specifically, pain was associated with reduced overall survival. In a subset of the cohort with endometrial cancer, a number of QoL domains including overall QoL, physical, emotional and role functioning, nausea and vomiting, pain, dyspnoea, and appetite loss were independently associated with survival [26]. 


\section{Case series}

Three studies recruited prostate and pancreatic cancer patients consecutively [32-34]. In the context of radiotherapy, overall survival and disease-free survival in prostate cancer patients with localised disease were predicted by socioeconomic status, psychological factors and patient self-reported QoL [32]. In this study, different QoL domains demonstrated favourable or unfavourable impact; patients with reports of few or no physical complaints predicted shorter survival whereas reported pain was prognostic for longer overall survival.

A case series of 55 pancreatic cancer patients identified a borderline significant association between baseline health and physical measures and survival after adjustment for disease stage at diagnosis [33]. Indeed, this study also suggested that patient satisfaction with QoL provides useful prognostic information.

\section{Discussion}

This systematic review identified several domains of QoL as potential prognosticators for oncological outcomes in tumours of the pelvic abdominal cavity. Specifically, global QoL, physical and role functioning, and fatigue consistently emerged as independent prognostic factors for overall and disease-free survival across the included tumour types [14, 18, 19, 22, 26, 29-31, 33]. Other domains relating to pain, constipation, dyspnoea, anorexia and cognitive function also appeared to have a potential prognostic function, independently of the clinicopathological features of disease [14-16, 19, 24, 29].

Despite compelling published evidence observing the prognostic role of baseline QoL measurements, the causal relationship between QoL and overall survival remains enigmatic. It has previously been suggested that collection of self-report QoL measurements may indicate the underlying severity of disease more accurately than other crude clinical measurements such as tumour burden [35]. Indeed, previously published studies have observed the superior nature of QoL in assessing prognosis compared to tumour burden; Earlam et al. successfully utilised physical QoL score to predict the overall survival of colorectal patients with liver metastases receiving supportive care alone and identified that the extent of metastasis did not influence survival [36]. In addition, historical studies in lung cancer $[37,38]$ identified QoL as an independent prognostic factor for survival, but failed to identify a significant relationship between survival and number of metastatic sites or disease extent. It is hypothesised that tumour markers which accurately reflect tumour aggression may also impact patient QoL more significantly than tumour burden [30].

Equally, various studies have hypothesised that QoL may directly impact tumour behaviour and subsequent patient survival, although such evidence is limited and controversial. Various studies [39-41] suggested that improvements in QoL or patient mental and emotional wellbeing may influence survival, but were limited by small patient numbers. In comparison a larger study of more than 1000 head and neck cancer patients found no link between emotional wellbeing and survival in this patient group [42]. Overall, the potential underlying mechanistic action of QoL monitoring and impact on patient survival requires more investigation.

Despite the evident prognostic potential of PROMs, our overview of the literature suggests that most PROMs are collected in the context of scientific research rather than routinely in the cancer clinical setting. Although it is well-established that patient perspective is an integral component of high quality and patient-centred care [43], financial burden and logistical issues prevent many healthcare systems from adopting PROM collection [10], and there exists a lack of uniform approach for their implementation in cancer specifically [11]. The PRISMA study, which primarily surveyed clinicians from Europe or Africa, highlighted physician time constraints and patient factors as key barriers to PROM implementation within the palliative care setting [44]. Additionally, a lack of training and guidance for clinicians were identified in this study as factors preventing wide-spread roll-out, and Gibbons et al. identified difficulties relating to budget and available software tools as further barriers to successful implementation [45].

There also exists a lack of validated tumour specific outcome measurement tools in cancer. Within this review, the majority of studies utilised baseline measurements of the cancer generic EORTC QLQ-C30 instrument. Although a standard tool for measuring HRQoL, the instrument lacks sensitivity to subtle disease specific changes [46]. Importance therefore lies with the development and validation of disease specific instruments which can detect and quantify disease subtle changes and accurately inform treating clinicians and the patients [47].

It is also of note that this review was undertaken during the COVID-19 pandemic when fears around the longer-term burden of SARS-CoV-2 on cancer care were emerging. During the outbreak, outpatient cancer care underwent a perhaps perpetual paradigm shift towards remote telemedicine, which further highlighted the necessity of routine collection of PROMs to support patients and allow shared clinical decision-making.

\section{Limitations}

Many of the analyses included large patient numbers and therefore the findings of this review can be assumed robust. There did, however, exist heterogeneity in the 
study design and methodology of the included studies which ultimately prohibited a collective meta-analysis of the reported data. Ten of the included studies were conducted using data collated in the United States where private health care is prevalent, and therefore the results of these studies may not be generalisable across other populations. Equally, most of the included analyses (13/21) covered pancreatic and prostate tumour types alone. Although the shorter and longer survival times associated with these cancers provide a comprehensive overview of quality of life across the full cancer journey, these cancers are analogous with a specific age range and the male sex. Therefore, the prognostic potential of QoL measures is less well understood in other tumour types of the pelvic abdominal cavity and may differ by sex and age. Further investigation into the prognostic potential of PROMs is warranted in such tumour types with limited existing evidence.

\section{Conclusions}

Overall, the findings of this review suggest a role for the routine collection of baseline PROMs in tumours of the pelvic abdominal cavity to improve both patient quality of life and outcomes. Specifically, global QoL, physical and role functioning and fatigue consistently emerged as independent prognosticators indicative of survival across these tumour types.

\section{Supplementary Information}

The online version contains supplementary material available at https://doi. org/10.1186/s12955-020-01648-x.

Additional file 1: Appendices A, B1, B2 and B3 detailing the search strategy and $\mathrm{JB}$ quality assessments of each included study.

\section{Acknowledgements}

Not applicable.

\section{Authors' contributions}

Review design: CM, AA, AQ, BT, TGU, MVH. Systematic searching, screening, and data extraction: $\mathrm{CM}, \mathrm{MVH}$. Quality assessment: $\mathrm{CM}, \mathrm{MVH}$. Preparation of manuscript: CM, TGU, MVH. Critical review of manuscript: CM, AA, AQ, BT, TGU, $\mathrm{MVH}$. All authors read and approved the final manuscript.

\section{Funding}

AA is supported by a National Institute for Health Research (NIHR) Advanced Fellowship (NIHR300599).

\section{Availability of data and materials}

Data sharing is not applicable to this article as no datasets were generated or analysed during the current study.

\section{Ethics approval and consent to participate} Not applicable.

\section{Consent for publication}

Not applicable.

\section{Competing interests}

The authors declare that they have no competing interests.

\section{Author details}

${ }^{1}$ King's College London, School of Cancer and Pharmaceutical Sciences, Translational Oncology and Urology Research (TOUR), Guy's Hospital, 3rd Floor Bermondsey Wing, Great Maze Pond, London SE1 9RT, UK. ${ }^{2}$ Comprehensive Cancer Centre, Guy's and St Thomas' NHS Foundation Trust, London, UK. ${ }^{3}$ Department of Health Services Research and Policy, London School of Hygiene and Tropical Medicine, London, UK.

Received: 3 September 2020 Accepted: 9 December 2020

Published online: 15 January 2021

\section{References}

1. Ferlay J, Soerjomataram I, Dikshit R, Eser S, Mathers C, Rebelo M, et al. Cancer incidence and mortality worldwide: sources, methods and major patterns in GLOBOCAN 2012. Int J Cancer. 2015;136(5):E359-86.

2. UK CR. https://www.cancerresearchuk.org/health-professional/cance r-statistics/survival/common-cancers-compared\#ref-1.

3. Ahmed S, Berzon RA, Revicki DA, Lenderking WR, Moinpour CM, Basch $E$, et al. The use of patient-reported outcomes (PRO) within comparative effectiveness research: implications for clinical practice and health care policy. Med Care. 2012;50(12):1060-70.

4. FDA. Guidance for Industry Patient-Reported Outcomes Measures Use in medical product development to support labeling claims. Clin FED Regist 2009. 2009:1-39.

5. Kotronoulas G, Kearney N, Maguire R, Harrow A, Di Domenico D, Croy S, et al. What is the value of the routine use of patient-reported outcome measures toward improvement of patient outcomes, processes of care, and health service outcomes in cancer care? A systematic review of controlled trials. J Clin Oncol. 2014;32(14):1480-501.

6. Ruland $\mathrm{CM}$, Holte HH, Roislien J, Heaven C, Hamilton GA, Kristiansen J, et al. Effects of a computer-supported interactive tailored patient assessment tool on patient care, symptom distress, and patients' need for symptom management support: a randomized clinical trial. J Am Med Inform Assoc. 2010;17(4):403-10.

7. Au HJ, Ringash J, Brundage M, Palmer M, Richardson H, Meyer RM, et al. Added value of health-related quality of life measurement in cancer clinical trials: the experience of the NCIC CTG. Expert Rev Pharmacoecon Outcomes Res. 2010;10(2):119-28.

8. Mercieca-Bebber R, King MT, Calvert MJ, Stockler MR, Friedlander M. The importance of patient-reported outcomes in clinical trials and strategies for future optimization. Patient Relat Outcome Meas. 2018;9:353-67.

9. Basch E. Toward patient-centered drug development in oncology. N Engl J Med. 2013;369(5):397-400.

10. Squitieri L, Bozic KJ, Pusic AL. The role of patient-reported outcome measures in value-based payment reform. Value Health. 2017;20(6):834-6.

11. Prodinger B, Taylor P. Improving quality of care through patient-reported outcome measures (PROMs): expert interviews using the NHS PROMs Programme and the Swedish quality registers for knee and hip arthroplasty as examples. BMC Health Serv Res. 2018;18(1):87.

12. Geerse OP, Brandenbarg D, Kerstjens HAM, Berendsen AJ, Duijts SFA, Burger $\mathrm{H}$, et al. The distress thermometer as a prognostic tool for one-year survival among patients with lung cancer. Lung Cancer. 2019;130:101-7.

13. Kerrigan K, Patel SB, Haaland B, Ose D, Weinberg Chalmers A, Haydell T, et al. Prognostic significance of patient-reported outcomes in cancer. JCO Oncol Pract. 2020;16(4):e313-23.

14. Bingener J, Sloan JA, Novotny PJ, Pockaj BA, Nelson H. Perioperative patient-reported outcomes predict serious postoperative complications: a secondary analysis of the COST trial. J Gastrointest Surg. 2015;19(1):6571; discussion

15. Bernhard J, Dietrich D, Glimelius B, Hess V, Bodoky G, Scheithauer W, et al. Estimating prognosis and palliation based on tumour marker CA 19-9 and quality of life indicators in patients with advanced pancreatic cancer receiving chemotherapy. Br J Cancer. 2010;103(9):1318-24.

16. Gourgou-Bourgade S, Bascoul-Mollevi C, Desseigne F, Ychou M, Bouche O, Guimbaud R, et al. Impact of FOLFIRINOX compared with gemcitabine 
on quality of life in patients with metastatic pancreatic cancer: results from the PRODIGE 4/ACCORD 11 randomized trial. J Clin Oncol. 2013;31(1):23-9.

17. Stucky CC, Pockaj BA, Novotny PJ, Sloan JA, Sargent DJ, O'Connell MJ, et al. Long-term follow-up and individual item analysis of quality of life assessments related to laparoscopic-assisted colectomy in the COST trial 93-46-53 (INT 0146). Ann Surg Oncol. 2011;18(9):2422-31.

18. Chau I, Norman AR, Cunningham D, Waters JS, Oates J, Ross PJ. Multivariate prognostic factor analysis in locally advanced and metastatic esophago-gastric cancer-pooled analysis from three multicenter, randomized, controlled trials using individual patient data. J Clin Oncol. 2004;22(12):2395-403

19. Roychowdhury DF, Hayden A, Liepa AM. Health-related quality-of-life parameters as independent prognostic factors in advanced or metastatic bladder cancer. J Clin Oncol. 2003;21(4):673-8.

20. Collette L, van Andel G, Bottomley A, Oosterhof GO, Albrecht W, de Reijke TM, et al. Is baseline quality of life useful for predicting survival with hormone-refractory prostate cancer? A pooled analysis of three studies of the European Organisation for Research and Treatment of Cancer Genitourinary Group. J Clin Oncol. 2004;22(19):3877-85.

21. Quinten C, Martinelli F, Coens C, Sprangers MA, Ringash J, Gotay C, et al. A global analysis of multitrial data investigating quality of life and symptoms as prognostic factors for survival in different tumor sites. Cancer. 2014;120(2):302-11

22. de Rooij BH, Thong MSY, van Roij J, Bonhof CS, Husson O, Ezendam NPM. Optimistic, realistic, and pessimistic illness perceptions; quality of life; and survival among 2457 cancer survivors: the population-based PROFILES registry. Cancer. 2018;124(17):3609-17.

23. Graham J, Gingerich J, Lambert P, Alamri A, Czaykowski P. Baseline Edmonton Symptom Assessment System and survival in metastatic renal cell carcinoma. Curr Oncol. 2018:25(4):e319-23.

24. Baekelandt BM, Hjermstad MJ, Nordby T, Fagerland MW, Kure EH, Heiberg T, et al. Preoperative cognitive function predicts survival in patients with resectable pancreatic ductal adenocarcinoma. HPB (Oxford). 2016;18(3):247-54.

25. Moningi S, Walker AJ, Hsu CC, Reese JB, Wang JY, Fan KY, et al. Correlation of clinical stage and performance status with quality of life in patients seen in a pancreas multidisciplinary clinic. J Oncol Pract. 2015;11(2):e216-21.

26. Robinson KM, Christensen KB, Ottesen B, Krasnik A. Diagnostic delay, quality of life and patient satisfaction among women diagnosed with endometrial or ovarian cancer: a nationwide Danish study. Qual Life Res. 2012;21(9):1519-25

27. Gupta D, Patel K, Lis CG. Self-rated health supersedes patient satisfaction with service quality as a predictor of survival in prostate cancer. Health Qual Life Outcomes. 2015:13:137.

28. Jayadevappa R, Chhatre S, Wein AJ, Malkowicz SB. Predictors of patient reported outcomes and cost of care in younger men with newly diagnosed prostate cancer. Prostate. 2009:69(10):1067-76

29. Braun DP, Gupta D, Staren ED. Longitudinal health-related quality of life assessment implications for prognosis in stage IV pancreatic cancer Pancreas. 2013;42(2):254-9.

30. Maisey NR, Norman A, Watson M, Allen MJ, Hill ME, Cunningham D. Baseline quality of life predicts survival in patients with advanced colorectal cancer. Eur J Cancer. 2002;38(10):1351-7.

31. Coates A, Porzsolt F, Osoba D. Quality of life in oncology practice: prognostic value of EORTC QLQ-C30 scores in patients with advanced malignancy. Eur J Cancer. 1997;33(7):1025-30.
32. Lehto US, Ojanen M, Vakeva A, Dyba T, Aromaa A, Kellokumpu-Lehtinen P. Early quality-of-life and psychological predictors of disease-free time and survival in localized prostate cancer. Qual Life Res. 2019;28(3):677-86.

33. Lis CG, Gupta D, Grutsch JF. Patient satisfaction with quality of life as a predictor of survival in pancreatic cancer. Int J Gastrointest Cancer. 2006;37(1):35-44

34. Lis CG, Gupta D, Grutsch JF. Patient satisfaction with health-related quality of life: implications for prognosis in prostate cancer. Clin Genitourin Cancer. 2008:6(2):91-6.

35. Djarv T, Metcalfe C, Avery KN, Lagergren P, Blazeby JM. Prognostic value of changes in health-related quality of life scores during curative treatment for esophagogastric cancer. J Clin Oncol. 2010;28(10):1666-70.

36. Earlam S, Glover C, Fordy C, Burke D, Allen-Mersh TG. Relation between tumor size, quality of life, and survival in patients with colorectal liver metastases. J Clin Oncol. 1996;14(1):171-5

37. Ganz PA, Lee JJ, Siau J. Quality of life assessment. An independent prognostic variable for survival in lung cancer. Cancer. 1991;67(12):3131-5.

38. Kaasa S, Mastekaasa A, Lund E. Prognostic factors for patients with inoperable non-small cell lung cancer, limited disease. The importance of patients'subjective experience of disease and psychosocial well-being. Radiother Oncol. 1989;15(3):235-42.

39. Spiegel D, Bloom JR, Kraemer HC, Gottheil E. Effect of psychosocial treatment on survival of patients with metastatic breast cancer. Lancet. 1989;2(8668):888-91.

40. Spiegel D, Sephton SE, Terr Al, Stites DP. Effects of psychosocial treatment in prolonging cancer survival may be mediated by neuroimmune pathways. Ann N Y Acad Sci. 1998:840:674-83.

41. Fawzy Fl, Fawzy NW, Hyun CS, Elashoff R, Guthrie D, Fahey JL, et al. Malignant melanoma. Effects of an early structured psychiatric intervention, coping, and affective state on recurrence and survival 6 years later. Arch Gen Psychiatry. 1993;50(9):681-9.

42. Coyne JC, Pajak TF, Harris J, Konski A, Movsas B, Ang K, et al. Emotional well-being does not predict survival in head and neck cancer patients: a Radiation Therapy Oncology Group study. Cancer. 2007;1 10(11):2568-75.

43. Fix GM, VanDeusen LC, Bolton RE, Hill JN, Mueller N, LaVela SL, et al. Patient-centred care is a way of doing things: how healthcare employees conceptualize patient-centred care. Health Expect. 2018;21(1):300-7.

44. Bausewein C, Simon ST, Benalia H, Downing J, Mwangi-Powell FN, Daveson BA, et al. Implementing patient reported outcome measures (PROMs) in palliative care-users' cry for help. Health Qual Life Outcomes. 2011;9:27.

45. Gibbons E, Fitzpatrick R. An alternative approach to implementing patient-reported outcome measures. Pilot Feasibility Stud. 2018;4:96.

46. Bouazza YB, Chiairi I, El Kharbouchi O, De Backer L, Vanhoutte G, Janssens A, et al. Patient-reported outcome measures (PROMs) in the management of lung cancer: a systematic review. Lung Cancer. 2017;113:140-51.

47. Weldring T, Smith SM. Patient-reported outcomes (PROs) and patientreported outcome measures (PROMs). Health Serv Insights. 2013;6:61-8.

\section{Publisher's Note}

Springer Nature remains neutral with regard to jurisdictional claims in published maps and institutional affiliations.

Ready to submit your research? Choose BMC and benefit from

- fast, convenient online submission

- thorough peer review by experienced researchers in your field

- rapid publication on acceptance

- support for research data, including large and complex data types

- gold Open Access which fosters wider collaboration and increased citations

- maximum visibility for your research: over 100M website views per year

At $\mathrm{BMC}$, research is always in progress.

Learn more biomedcentral.com/submissions 